\title{
Recidiva paraesofágica de hernia hiatal. Diagnóstico radiológico y resolución quirúrgica laparoscópica
}

Paraesophageal recurrence of hiatal hernia. Radiological diagnosis and laparoscopic surgical resolution

Recorrência paraesofágica de hérnia hiatal. Diagnóstico radiológico e resolução cirúrgica laparoscópica

Martín Varela ${ }^{1}$

ORCID 0000-0003-2376-2844

martinvarelav@gmail.com

Nicolás Muniz ${ }^{2}$

ORCID 0000-0002-6235-1303

nicomuniz@hotmail.com

Andrés Pouy ${ }^{3}$

ORCID 0000-0002-7136-144X

andrespouy@hotmail.com
Camila Haro ${ }^{4}$

ORCID 0000-0003-4475-9740

harob.camila@gmail.com

Sofía Mansilla ${ }^{5}$

ORCID 0000-0002-5881-9284

sofiamansillarud@gmail.com

DOI 10.31837/cir.urug/6.1.6

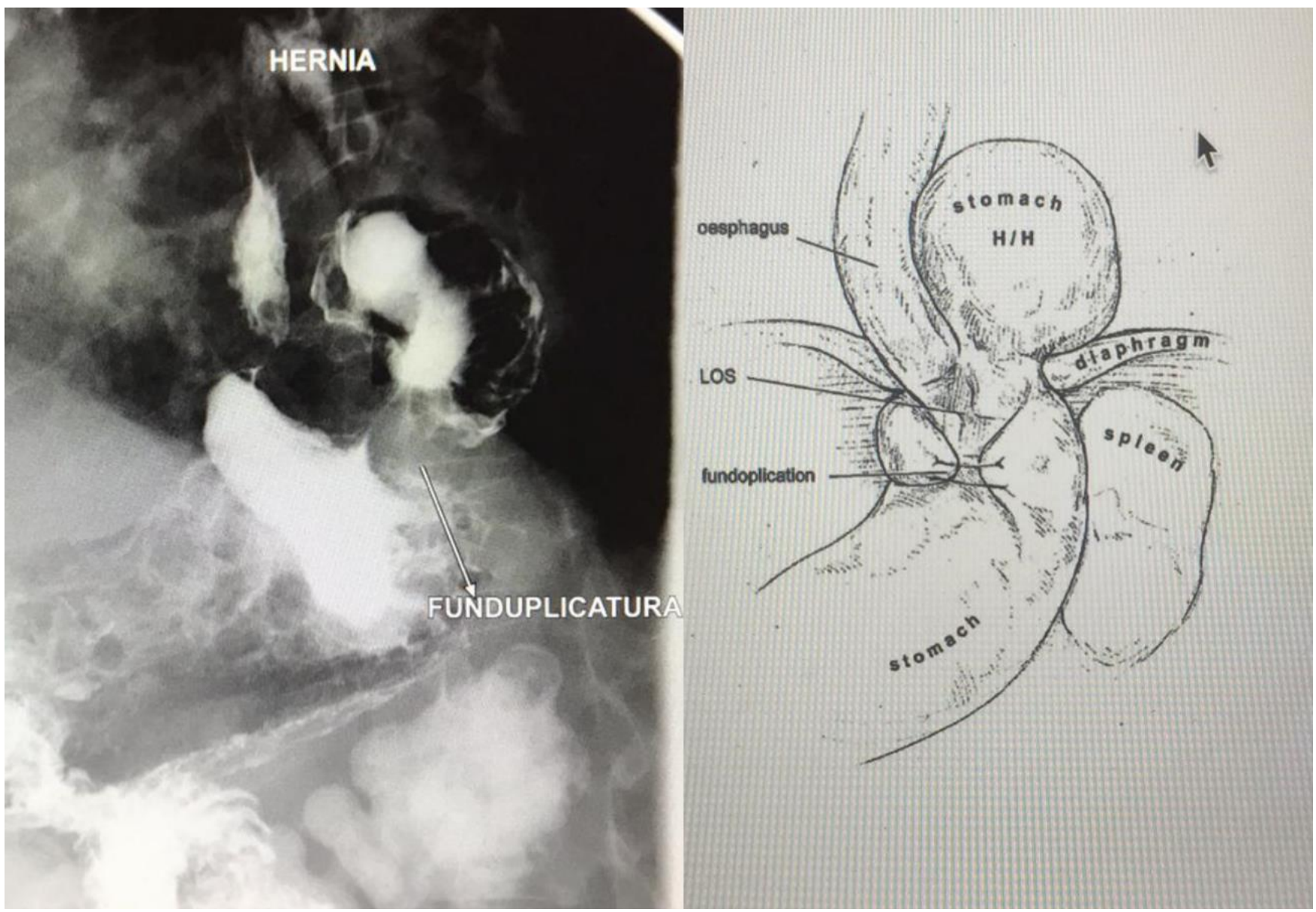

1,2,3,4,5 Clínica Quirúrgica B, Hospital de Clínicas, Facultad de Medicina, Universidad de la República, Montevideo, Uruguay 
Recibido: 27 de abril de 2021

Aceptado: 20 de diciembre de 2021

Ilustración tomada de: Suppiah A. et als. Temporal patterns of hiatus hernia recurrence and hiatal failure: quality of life and recurrence after revision surgery. Dis Esophagus. 2017 Apr 1;30(4):1-8.

La tasa de recidiva radiológica luego de la cirugía de las hernias hiatales grandes tipo IV es cercana al 50\%. La mayoría de las veces la recidiva supone un ascenso parcial de la funduplicatura al tórax (telescopaje), y si no tiene expresión clínica puede optarse por un manejo conservador (solo 3-6\% requieren cirugía de revisión). Sin embargo, en ocasiones hay otro tipo de recidivas (paraesofágicas) que deben valorarse mediante estudios funcionales, endoscópicos y radiológicos, que dan disfagia con mayor frecuencia.

Un tránsito contrastado digestivo superior permite en este caso identificar el tipo de recidiva herniaria, con migración parcial del fundus gástrico hacia el tórax paraesofágico izquierdo, y una funduplicatura continente pero realizada técnicamente en por debajo de lo deseable (cuerpo alto) (figura).

La resolución del cuadro implica la reducción de la hernia a la cavidad abdominal, con cierre del defecto diafragmático, desmontar la funduplicatura anterior anatomizando la zona y la reconfección de una nueva funduplicatura. 